\title{
Spatial Effects of Productive Service Industry Agglomeration on China's Provincial Economic Growth
}

\author{
Yue GAO * and Shujun AN \\ Northwest University, Xi'an, China; moon441@live.cn, xdasj@126.com \\ * Correspondence: moon441@ive.cn
}

\begin{abstract}
This paper uses Chinese provincial panel data from 2003-2013 to measure the degree of agglomeration of the productive service industries in China as a whole and the provinces using the spatial Gini coefficient. Next, on the basis of confirming the spatial correlation of inter-provincial economic growth in China, we use a spatial econometric analysis method to examine the spatial effect of productive service industry agglomeration within and between provinces on China's economic growth. This spatial effect is further decomposed into direct and indirect effects. The results of the study found that: (1) China's inter-provincial economic growth spatial correlation test confirmed that there was a significant spatial correlation in China's inter-provincial economic growth; (2) The agglomeration of productive services played a role in China's inter-provincial economic growth through spatial agglomeration significant impacts; (3) The inspection and decomposition of spatial effects show that the direct and indirect effects of productive service industry agglomeration on China's inter-provincial economic growth are significant, and the indirect effect is greater than the direct effect. There is a spatial spillover effect of economic growth, and the benefits of this agglomeration of productive service industries also spillover into neighboring regions with economic interaction.
\end{abstract}

Keywords: productive service industry agglomeration; spatial correlation; direct effect; indirect effect; spillover effect

JEL Classification: O14; O18; R12

\section{Introduction}

As the world economic structure shifts from an "industrial economy" to a "service economy," the role of services, especially the productive service industry, in economic growth has become more important. The agglomeration and growth level of the service industry has become an important indicator to measure the comprehensive competitiveness of the regional economy. The contribution rate of tertiary industry to GDP in China has gradually increased from about $28.49 \%$ in 1995 to $46.72 \%$ in 2013; the contribution of the growth of the productive service industry to GDP has increased from $18 \%$ in 1995 to $22 \%$ in 2013. However, compared with the world level, the degree of agglomeration and development scale of China's productive service industry is still low, and there are huge differences between provinces, which have different effects on provincial economic growth. In the world, the output value of the productive service industry generally exceeds $50 \%$ of the total output value of the service industry, while in China it is less than $30 \%$.

The agglomeration of economy is the key to promote economic growth. The agglomeration of productive service industry can promote regional economic growth through specialized division of labor, reducing intermediate service costs and transaction costs, exerting spatial externalities, generating competition effects and learning effect, technology spillover effects, and improving labor productivity.

A large number of studies at home and abroad have shown that the productive service industry has an industrial agglomeration effect, and has a significant driving effect on manufacturing production efficiency and economic growth (Jiang Jing et al. 2007; Zhan Haoyong 2013; Hanssens et al. 2013); it is 
helps to generate high-tech industries and achieve sustainable economic growth (Aslesen and Isaksen 2007). However, some studies suggest that the agglomeration of productive service industry has not significant promoted economic development, some other studies suggest that the impact of productive service industry agglomeration on economic growth is inverted U-shaped, with the marginal contribution increasing first and then decreasing (Han Feng et al. 2014). Hanssens et al. (2013) also demonstrated that there is a spatial and functional connection between producers and consumers in the productive service industry. Ying (2003) analyzed the spatial lag model of provincial data in China and found that there is a spatial correlation between the GDP growth of each province.

Regional spatial differences are an important factor in the study of regional economic growth, but the potential interactions between regions are often ignored. Some of the existing researches ignored the spatial correlation of the interpreted variables, that is, the level of regional economic growth. Some literatures using spatial economic models ignore the spatial interactions of agglomeration of productive services as explanatory variables. In view of this, based on previous research, this paper will try to test the impact of productive service industry agglomeration on China's inter-provincial economic growth from the spatial dimension, and further consider the productive service industry agglomeration into the analysis framework of regional economic growth. By constructing a spatial panel measurement model, we use the panel data of 31 provinces and municipalities in China to test and decompose the spatial effects of factors such as the agglomeration of productive service industries that have a spatial impact on inter-provincial economic growth in China. This paper will mainly explore the following questions: (1) Is there exist a spillover in the productive service industry agglomeration area? (2) Are there exist spatial correlation in economic growth between neighboring provinces? (3) Is the spatial interaction of economic growth between provinces caused by the spillover of productive service industry agglomeration area to adjacent areas?

\section{Methodology, Model Settings and Data Description}

According to the employment statistics of China's sub-sectors, among the 14 service industries in the statistical yearbook of China, we divide them into three categories: producer service industry, consumer service industry and public service industry. Among them, producer services mainly refer to those service industries that provide service activities to other productive sectors that can be used in the production process of their products, and are characterized by high concentration, high knowledge and high economic radiation. Productive services include: transportation, warehousing and postal services; information transmission, computer services and software; finance; real estate; leasing and business services; scientific research, technical services and geological surveys. Consumer services include: wholesale and retail; accommodation and catering. Public services include: water conservancy; environment and public facilities management; health, social security and social welfare; culture, sports and entertainment; public management and social organization.

\subsection{Measurement of productive service industries in China}

There are different methods for the measurement of industries agglomeration based on varies angles. The measurement indicators mainly include the spatial Gini coefficient, Herfindahl index, E-G index, and location entropy. Due to the limitation of data availability, this paper uses Krugman (1991) and others to measure the degree of industrial agglomeration of manufacturing industry in the United States to measure the degree of industrial spatial distribution uniformity, and only selects the spatial Gini coefficient to measure the degree of producer service industry agglomeration in all provinces of China. Assuming that an economy (country or region) can be divided into $\mathrm{n}$ regions, the formula for calculating the spatial Gini coefficient of the economy is:

$$
G i N i=\sum_{i}^{n}\left(s_{i}-x_{i}\right)^{2}=\sum_{i}^{n}\left(\frac{s_{i j}}{\sum_{i} s_{i j}}-\frac{x_{i}}{\sum_{i} X_{i}}\right)^{2}
$$

Where, GiNi represents the spatial Gini coefficient, $s_{i}$ represents the proportion of employment in an industry in the region $i$ to the total employment in the economy, and $x_{i}$ represents the proportion of employment in the region $i$ to the total employment in the economy. $S_{i j}$ is the number of employees 
in the industry of $j$ in city $i$ of a province, $\sum_{i} S_{i j}$ is the number of employees in the industry of $j$ in all cities of the province, $X_{i}$ is the number of employees in the city of I in a province, and $\sum_{i} X_{i}$ is the number of employees in all cities of the province.

The value range of spatial Gini coefficient is $[0,1]$. The larger the coefficient is, the higher the degree of agglomeration is, and the smaller the coefficient is, the lower the degree of agglomeration is. A value of 0 indicates that the distribution of the industry in the economy is completely evenly distributed, and a value of 1 indicates that all production activities in the industry are concentrated in the same area.

1. China's overall productive services' spatial Gini coefficient

By calculating the spatial Gini coefficient of China's overall productive service industry from 2003 to 2013 as the Figure 1. It can be found that the overall agglomeration degree of China's productive service industry shows an upward trend of volatility.

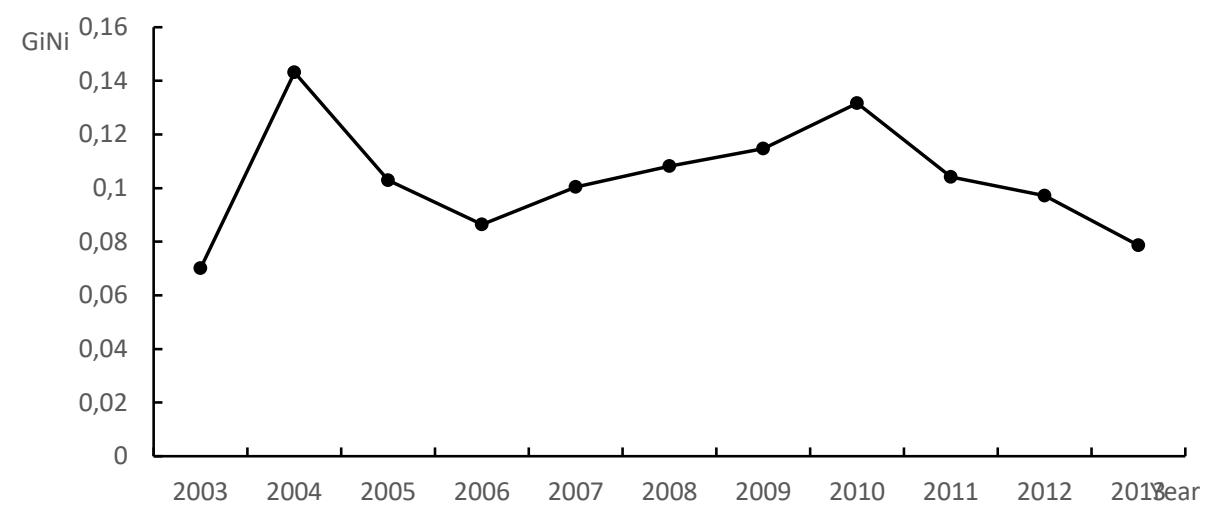

Figure 1. Spatial Gini coefficient of producer services in China, 2003-2013. Based on the relevant data of 286 cities at prefecture level and above in 2004-2014 China Statistical Yearbook, China Urban Statistical Yearbook and China regional economic statistical yearbook.

\section{Spatial Gini coefficient of China's productive services by sub-industry}

By calculating the spatial Gini coefficient of China's producer services from 2003 to 2013 as the Figure 2. It can be found that the agglomeration degree of different industries in China's producer services is not only different in the changing trend, but also in the absolute value. In these six industries, the spatial Gini coefficient of leasing and business service industry is the highest and fluctuates greatly, while the spatial Gini coefficient of financial industry is the lowest and changes slowly. In this paper, the calculation results of the spatial Gini coefficients of the six sub industries over the years are consistent with the analysis results of Chen Jianjun et al. (2009).

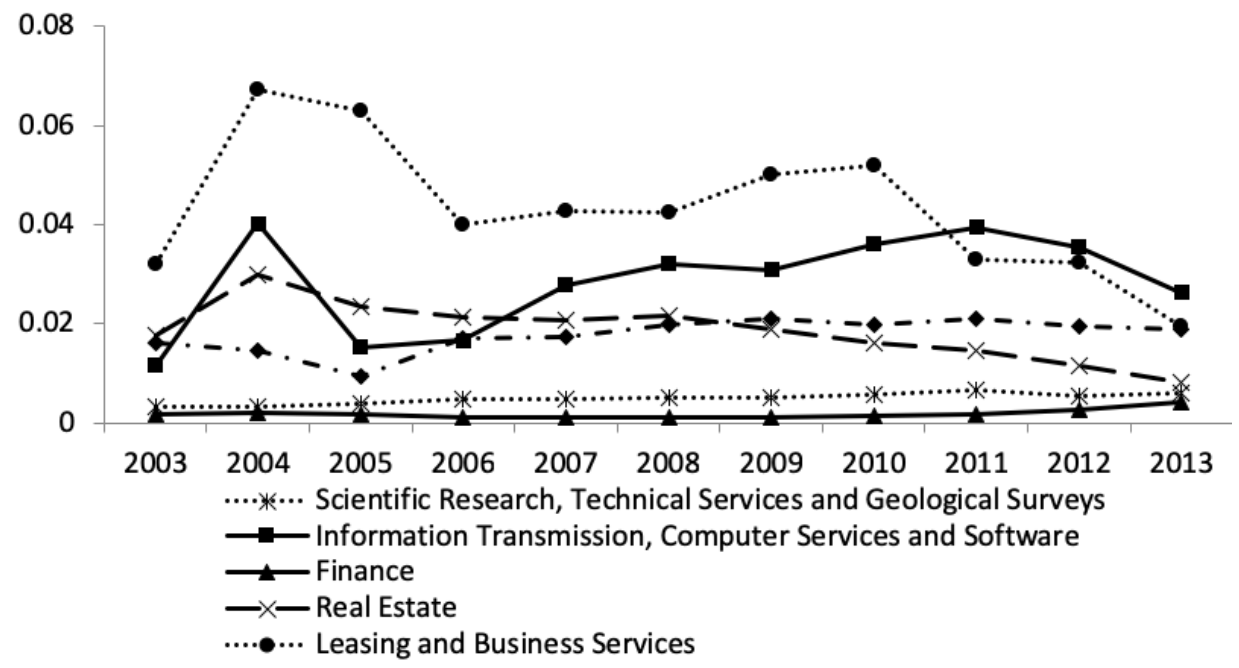

Figure 2. Spatial Gini coefficient of China's productive services by sub-sectors in 2003-2013. 


\section{Drawing maps}

Draw a quarter map of the spatial distribution of China's inter provincial producer services agglomeration in 2003, 2008 and 2013 as the Figure 3, Figure 4 and Figure 5. The darker the color, the higher the degree of the representative productive service industry agglomeration. It can be found that productive service cluster as a whole presents a ladder like spatial agglomeration structure from east to west and from south to north. The regions with high degree of agglomeration are mainly located in the Yangtze River Delta city group, Pearl River Delta Megalopolitan, Beijing-Tianjin-Hebei Megalopolitan, Shandong peninsula Megalopolitan and Chengdu-Chongqing Megalopolitan.

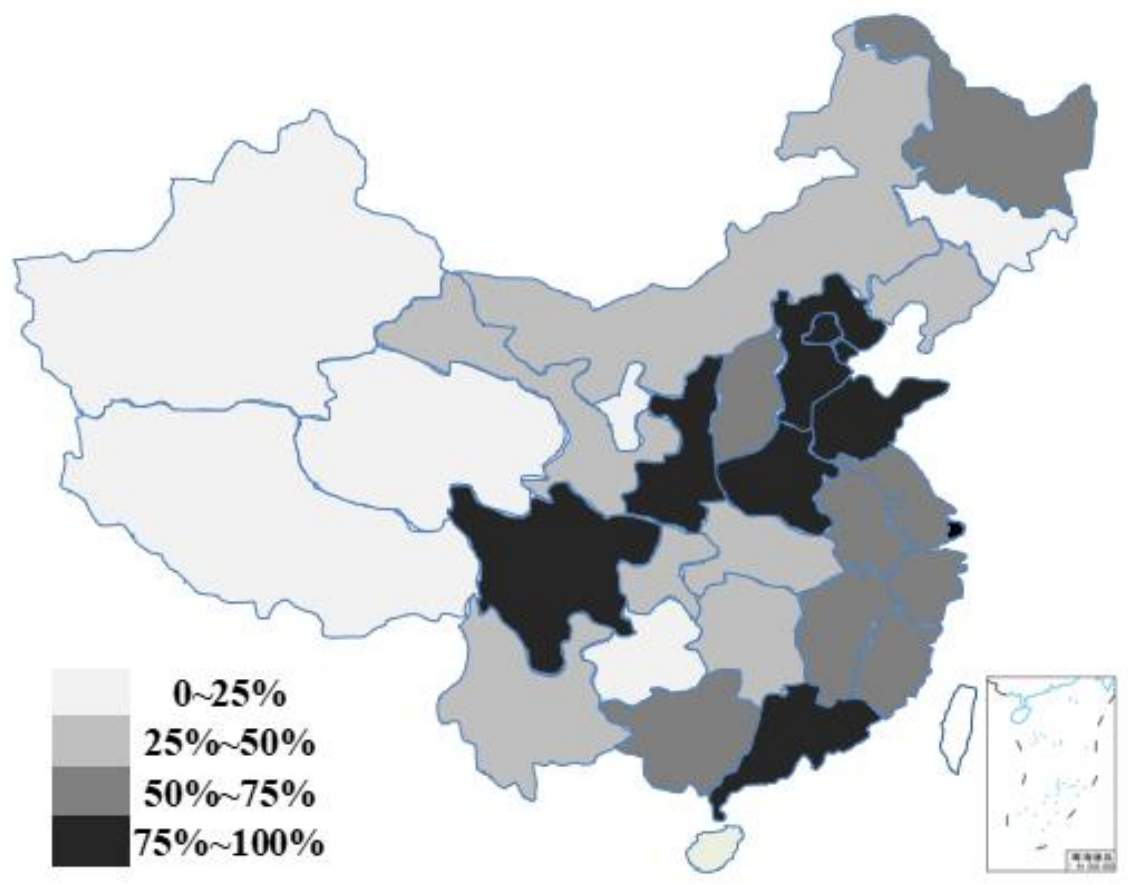

Figure 3. Spatial distribution of producer services in China in 2003.

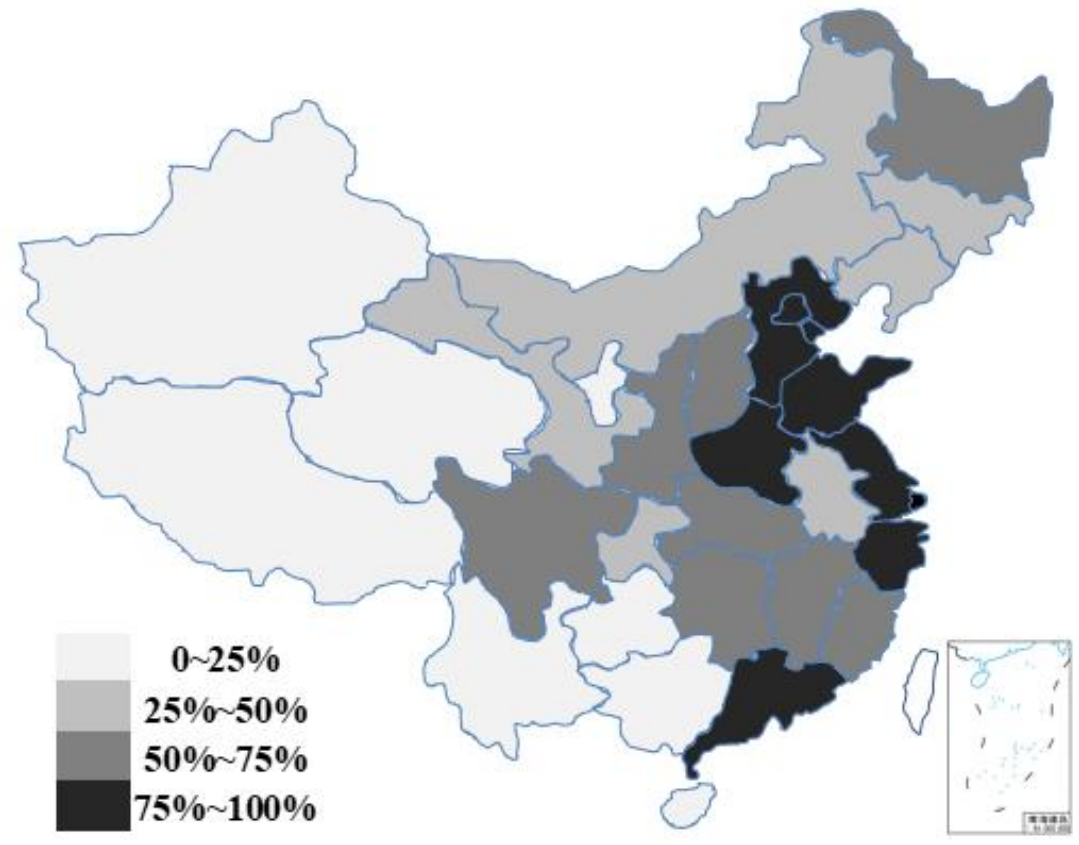

Figure 4. Spatial distribution of producer services in China in 2008. 


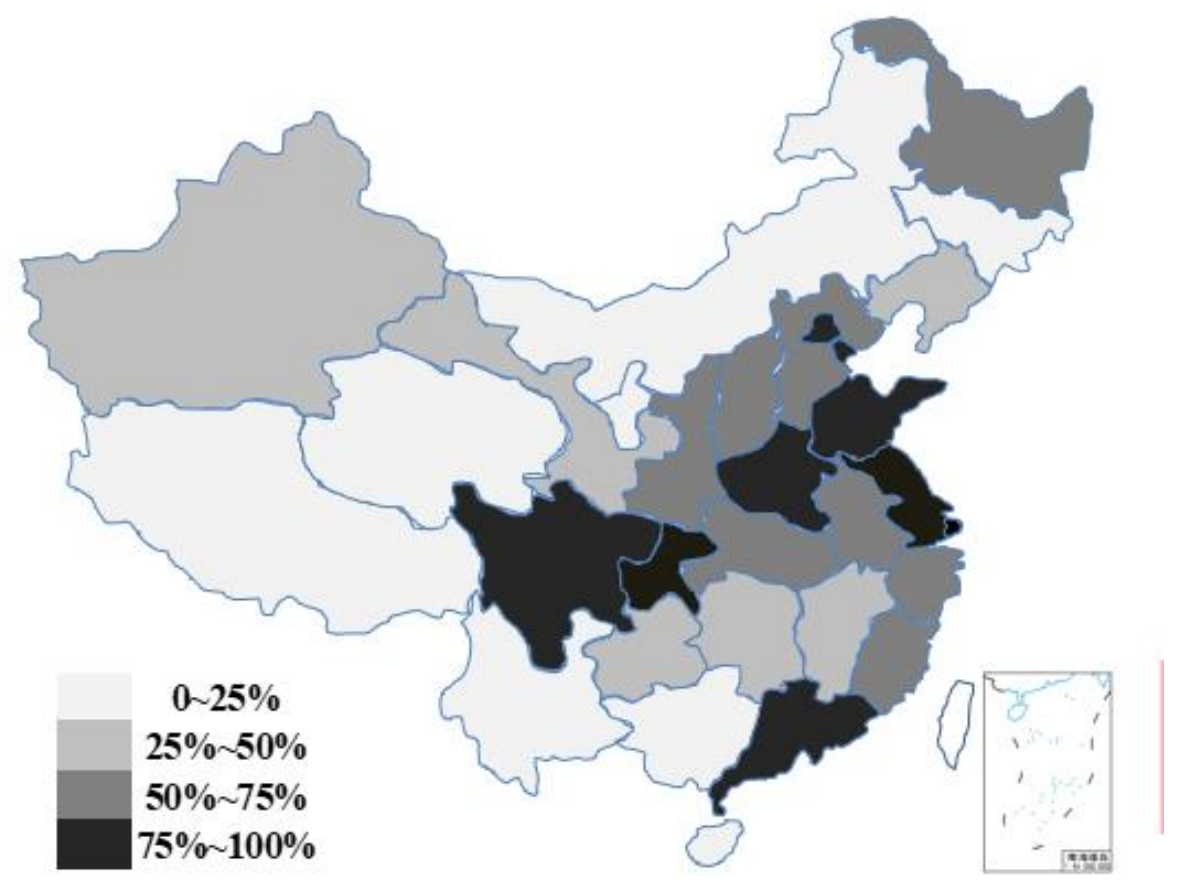

Figure 5. Spatial distribution of producer services in China in 2015.

From the above description, it can be found that productive service industry in China has the characteristics of spatial agglomeration, and the regions with high degree of agglomeration show a state of continuous agglomeration, while the economic development level and population agglomeration degree of these regions are high. It can be inferred that the development of China's inter- provincial productive service industry has obvious spatial correlation, and the spatial correlation is more significant in the regions with higher economic development level. Therefore, this paper will focus on the spatial effect of productive service industry agglomeration on China's inter-provincial economic growth.

\subsection{Basic model}

Establishing production function is the most commonly used method to estimate regional agglomeration effects. Based on the general research framework of measuring the relationship between industrial agglomeration and economic growth summarized by Rosenthal and strange (2004), this paper introduces the factors of industrial agglomeration and expresses the economic growth function as follows:

$$
Y_{i}=f\left(x_{i}\right) g\left(G_{i}\right)
$$

For simplicity, suppose that (2) is in the form of Cobb-Douglas production function, that is, $f\left(x_{i}\right)=A_{i} K_{i}^{\alpha} L_{i}^{\beta}$, and the function $g\left(G_{i}\right)$ also enters the production function in the form of product, and causes the change of the production function. Where, $Y_{i}$ represents the economic output of region $i$; $x_{i}$ represents the input variable, mainly including capital input factor $K_{i}$ and labor input factor $L_{i}$; $G_{i}$ represents the industrial agglomeration degree of region $i$, in this paper, it represents the agglomeration degree of productive service industry.

The expression (2) is expressed as per capita form and natural logarithm is taken, and the following basic function forms are obtained by further rewriting:

$$
\ln \left(\frac{Y_{i}}{L_{i}}\right)=\ln A_{i}+\alpha \ln \left(\frac{K_{i}}{L_{i}}\right)+(\alpha+\beta-1) \ln L_{i}+\gamma \ln G_{i}
$$

In addition to the above main factors, other factors input is also significantly related to regional economic growth. This paper refers to the research on regional economic growth by Brülhart and Sbergami (2009), and selects factors such as education, R \& D investment, government expenditure, 
infrastructure construction and the degree of opening-up as control variables in combination with the provincial characteristics of China. The basic form of panel data measurement model in this paper can be expressed as follows:

$$
\ln y_{i t}=a_{0}+a_{1} \ln k_{i t}+a_{2} \ln L_{i t}+a_{3} \ln G_{i t}+a_{4} Z_{i t}+\xi_{i t}
$$

Where, $y_{i t}$ is the per capita real GDP of region $i$ at period $t, k_{i t}$ is the per capita capital input of region $i$ at period $t, G_{i t}$ is the agglomeration degree of productive service industry in region $i$ at period $t$, and $Z_{i t}$ is the set of control variables, $a_{i}$ is the parameter with estimation, $\xi_{i t}=u_{i}+v_{t}+\varepsilon_{i t}$. Among them, $u_{i}$ is the individual effect, $v_{t}$ is the time effect, and $\varepsilon_{i t}$ is the random error term.

The formula (4) shows that the real GDP per capita in region $i$ is mainly affected by the degree of industrial agglomeration, capital input per capita, labor input and other input factors. In the above basic model, this paper focuses on the spatial impact of producer services agglomeration variable $G$ on provincial economic growth variables.

\subsection{Data description and variable description}

The research scope of this paper is 31 provinces, municipalities and autonomous regions in China. Hong Kong, Macao and Taiwan are excluded due to the availability of data and relatively poor economic connections with other provinces. In addition, since China adjusted the industry classification in 2003 and adjusted the service industry from the original 11 industries to the current 14 industries, in order to unify the statistical caliber and compare the sample data, the collection of data in various industries of the productive service industry started from 2003. Therefore, the provincial panel data from 2003 to 2013 and the panel data of 286 cities and above in China are finally used in this paper. All the data in this paper are mainly from China Statistical Yearbook and China City Statistical Yearbook over the years, and some of the data in some years and city characteristics are from China Education Funds Statistical Yearbook and China Regional Economic Statistical Yearbook. In order to increase the comparability and eliminate the influence of price factors, this paper uses the corresponding deflator to deflate the main research data.

In order to eliminate the heteroscedasticity in the estimation of production function, all variables are treated logarithmically in this paper. The construction and measurement of the main variables are described below. The statistical description of the main variables is shown in Table 1 .

Table 1. Statistical description of variables.

\begin{tabular}{|c|c|c|c|c|c|c|}
\hline Variables' Name & Variables & Unit & Mean & $\begin{array}{l}\text { Standard } \\
\text { Deviation }\end{array}$ & Minimum & Maximum \\
\hline $\begin{array}{l}\text { Per capita Real GDP } \\
\text { Per capita Total }\end{array}$ & rpGDP & yuan/person & 13248.86 & 7416.226 & 3685.633 & 38523.73 \\
\hline $\begin{array}{l}\text { Investment in Fixed } \\
\text { Assets of the whole } \\
\text { society }\end{array}$ & $\mathrm{k}$ & yuan/person & 12709.51 & 8344.245 & 1896.857 & 48089.59 \\
\hline $\begin{array}{c}\text { Proportion of Employees } \\
\text { in the Total Population at } \\
\text { the end of the year }\end{array}$ & L & $\%$ & 10.15091 & 6.947295 & 2.868217 & 57.09038 \\
\hline $\begin{array}{l}\text { Spatial Gini coefficient of } \\
\text { Productive Services }\end{array}$ & G & - & 0.0037 & 0.0153626 & $5.00 \mathrm{e}-06$ & 0.1307652 \\
\hline $\begin{array}{l}\text { Per capita Traffic Density } \\
\text { Per capita Total Business }\end{array}$ & trans & $\mathrm{km} / 10,000$ & 346589.4 & 336657.1 & 38171.64 & 2279275 \\
\hline $\begin{array}{l}\text { Volume of Post and } \\
\text { Telecommunications }\end{array}$ & mail & yuan/person & 1183.215 & 813.1196 & 258.4496 & 5571.48 \\
\hline $\begin{array}{l}\text { Per capita R\&D } \\
\text { Expenditure }\end{array}$ & $\mathrm{rd}$ & yuan/person & 389.025 & 646.0676 & 11.40506 & 4429.262 \\
\hline $\begin{array}{c}\text { Per capita Public } \\
\text { Financial Expenditure }\end{array}$ & gov & yuan/person & 4499.101 & 3514.964 & 741.2825 & 23984.19 \\
\hline
\end{tabular}


Per capita Total Import

and Export of Goods

open

yuan/person

11854.47

21764.32

210.5245

105085.4

Per capita Education

Expenditure

edu

yuan/person

1042.434

625.1801

246.5161

3737.015

Thus, the form of the common panel measurement model in this paper is set as follows:

$$
\begin{aligned}
& \operatorname{lnrpGDP}=\beta_{0}+\beta_{1} \operatorname{lnk}_{i t}+\beta_{2} \ln L_{i t}+\beta_{3} \ln G_{i t}+\beta_{4} \text { trans }_{i t}+\beta_{5} \text { mail }_{i t}+\beta_{6} r d_{i t}+\beta_{7} \text { gov }_{i t}+ \\
& \beta_{8} \text { open }_{i t}+\beta_{9} e d u_{i t}+u_{i}+v_{t}+\varepsilon_{i t}
\end{aligned}
$$

\section{Measurement Results and Analysis}

According to the first law of geography, there is a connection between anything and other things around it. Due to the existence of spatial heterogeneity and spatial correlation, time series regression method or common panel data analysis is no longer suitable to explain the complex relationship between productive service industry agglomeration and economic growth and the real economic connotation behind the variables. Therefore, this paper introduces spatial correlation analysis and uses spatial panel data model to study the spatial effect and heterogeneity of productive service industry agglomeration on inter-provincial economic growth in China.

\subsection{Spatial correlation analysis}

First of all, we will test whether the explained variables, that is, the real GDP per capita in China's provinces, have spatial autocorrelation from two aspects of global spatial autocorrelation and local spatial autocorrelation.

1. Global spatial autocorrelation test

The global spatial autocorrelation test can be performed by measuring the Moran's I index. The calculation formula is as follows:

$$
\text { Moran's } I=\frac{\sum_{i=1}^{n} \sum_{j=1}^{n} W_{i j}\left(Y_{i}-\bar{Y}\right)\left(Y_{j}-\bar{Y}\right)}{S^{2} \sum_{i=1}^{n} \sum_{j=1}^{n} W_{i j}}
$$

The range of the Moran's $I$ index is $-1 \leq I \leq 1$. When the value of $I$ is greater than 0 and close to 1 , it means that there is a positive spatial correlation between regions. When the value of $I$ is less than 0 and close to - 1 , it means that there is a negative spatial correlation between regions. When the value of $\mathrm{I}$ is close to 0 , it means that there is no spatial correlation between regions. Where, $S^{2}=$ $\frac{1}{n} \sum_{i=1}^{n}\left(Y_{i}-\bar{Y}\right)^{2}, \bar{Y}=\frac{1}{n} \sum_{i=1}^{n} Y_{i}$, and $Y_{i}$ means the per capita GDP of region $i, n$ is the total number of regions, and $W_{i j}$ is the element in the spatial weight matrix $W$, which can reflect the degree of interaction between adjacent or similar regions.

$$
w_{i j}= \begin{cases}1, & d_{i j}<d_{\text {min }} \\ 0, & d_{i j} \geq d_{\text {min }}\end{cases}
$$

Where, $d_{\min }$ is the threshold distance given in advance; $w_{i j}$ is the matrix element of row $i$ and column $j$, the elements on the diagonal are zero, and the elements in the matrix are used to reflect the spatial correlation between the two regions. In particular, $d_{i j}$ is the inter-provincial distance between region $i$ and region $j$. Considering that the majority of productive services activities are concentrated in the capital cities or municipalities directly under the central government of China, we build a spatial distance weight matrix based on the distance between the two regional capital cities (or municipalities directly under the central government) calculated from the longitude and latitude data of the two regions, which can more reflect the socio-economic characteristics of China's provinces. All spatial weighting matrices are row standardized.

We use Geoda1.10 software to analyze the Moran's I statistical value and Monte Carlo test as Table 2 for three equidistant years $(2003,2008$ and 2013). At the same time, according to the spatial 
correlation Moran's I index of China's per capita real GDP from 2003 to 2013, the Moran's I change trend chart of China's inter-provincial economic growth from 2003 to 2013 is drawn as Figure 6.

Table 2. Moran's I statistical value of real GDP per capita and its statistical test.

\begin{tabular}{cccccc}
\hline Year & Moran's I value & E (I) & Mean & $\begin{array}{c}\text { Standard } \\
\text { Deviation }\end{array}$ & P value \\
\hline 2003 & 0.3563 & -0.0333 & -0.0322 & 0.1359 & 0.0060 \\
2008 & 0.2932 & -0.0333 & -0.0270 & 0.1327 & 0.0120 \\
2013 & 0.2946 & -0.0333 & -0.0302 & 0.1353 & 0.0090 \\
\hline
\end{tabular}

${ }^{1}$ Monte Carlo tests all use a significance level of 0.001

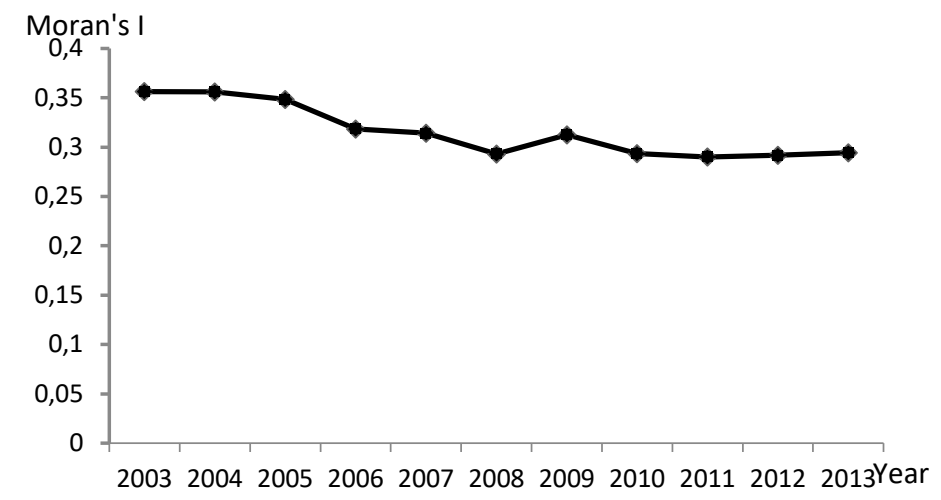

Figure 6. Moran's I change in real GDP per capita from 2003 to 2013.

The results in Table 2 and Figure 6 show that Moran's I statistics from 2003 to 2013 are both greater than 0 and less than 1 at a significant level of $1 \%$, indicating that China's real GDP per capita does have a spatial correlation and is a significant positive global autocorrelation. It shows that there is a spatial correlation between the real GDP per capita of 31 provinces and municipalities in China, which is suitable for spatial econometric analysis.

2. Local spatial autocorrelation test

In order to more clearly observe the spatial distribution and specific agglomeration characteristics of real GDP per capita, we use geoda1.10 software to draw Moran's I scatter diagram as Figure 7 and Lisa agglomeration diagram as Figure 6 of real GDP per capita in 2003, 2008 and 2013, respectively, to further test their local spatial correlation characteristics.
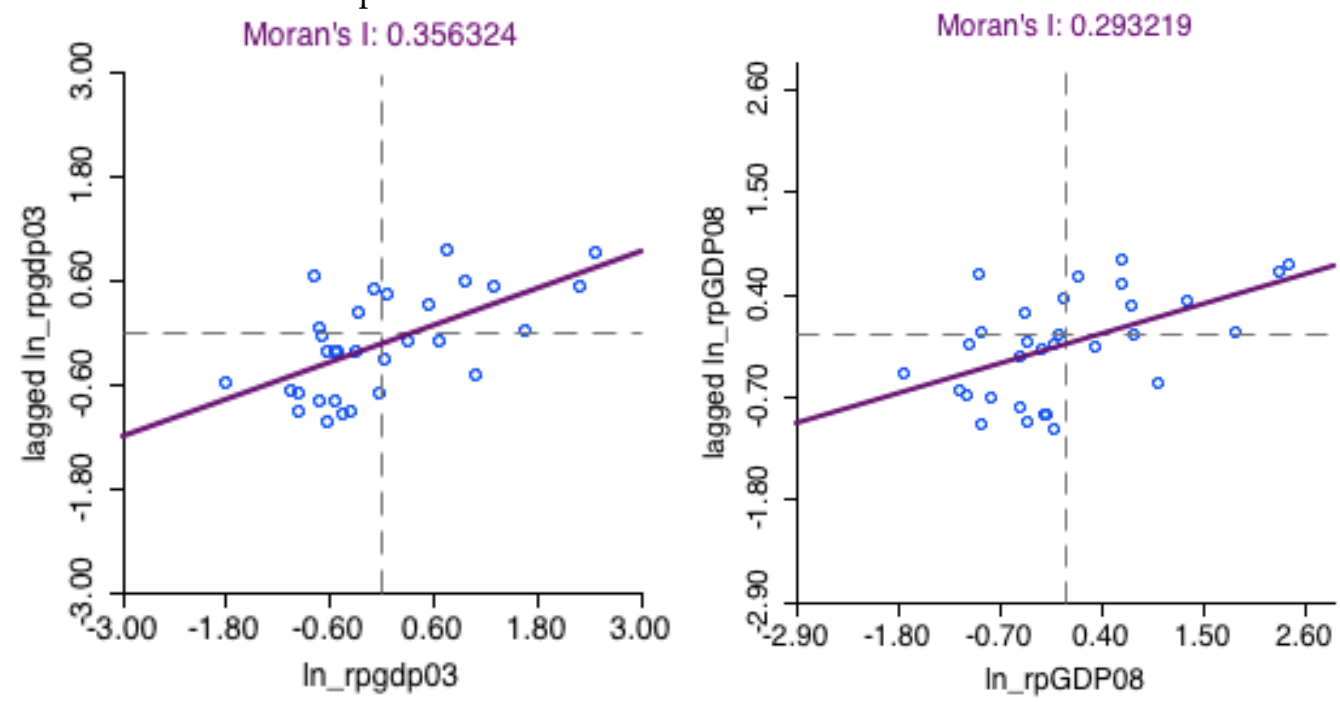


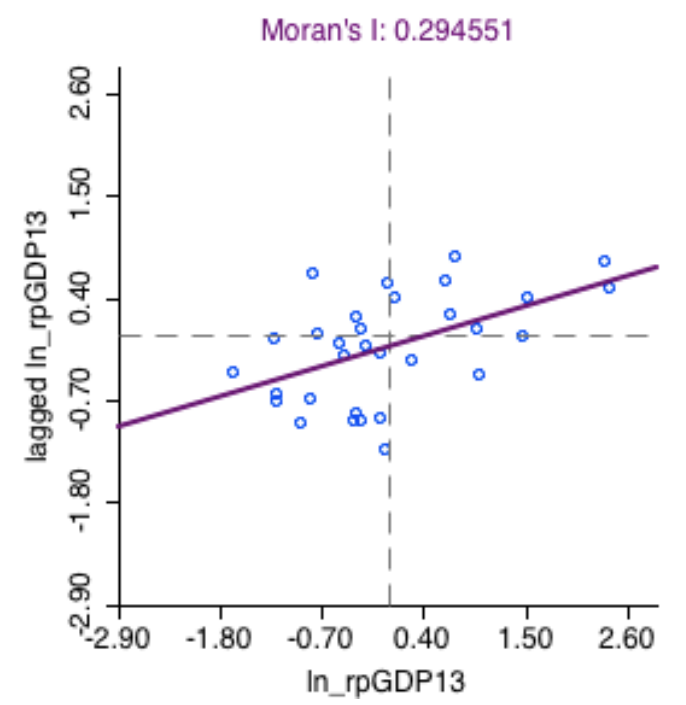

Figure 7. Comparison of scatter plots of Moran's I in2003, 2008 and 2013.

Each small circle in Moran's I scatter diagram represents a province (municipality or autonomous region), which can directly depict the heterogeneity of research objects in different regions. Among them, the first and the third quadrants indicate that there is a positive spatial correlation between the agglomeration areas, and the second and the fourth quadrants indicate that there is a negative spatial correlation between the agglomeration areas. It can be seen from Figure 7 that the observed values of real GDP per capita in three years are mostly distributed in the first and third quadrants, showing the phenomenon that regions with high concentration of real GDP per capita are adjacent to each other, and regions with low concentration of real GDP per capita are adjacent.

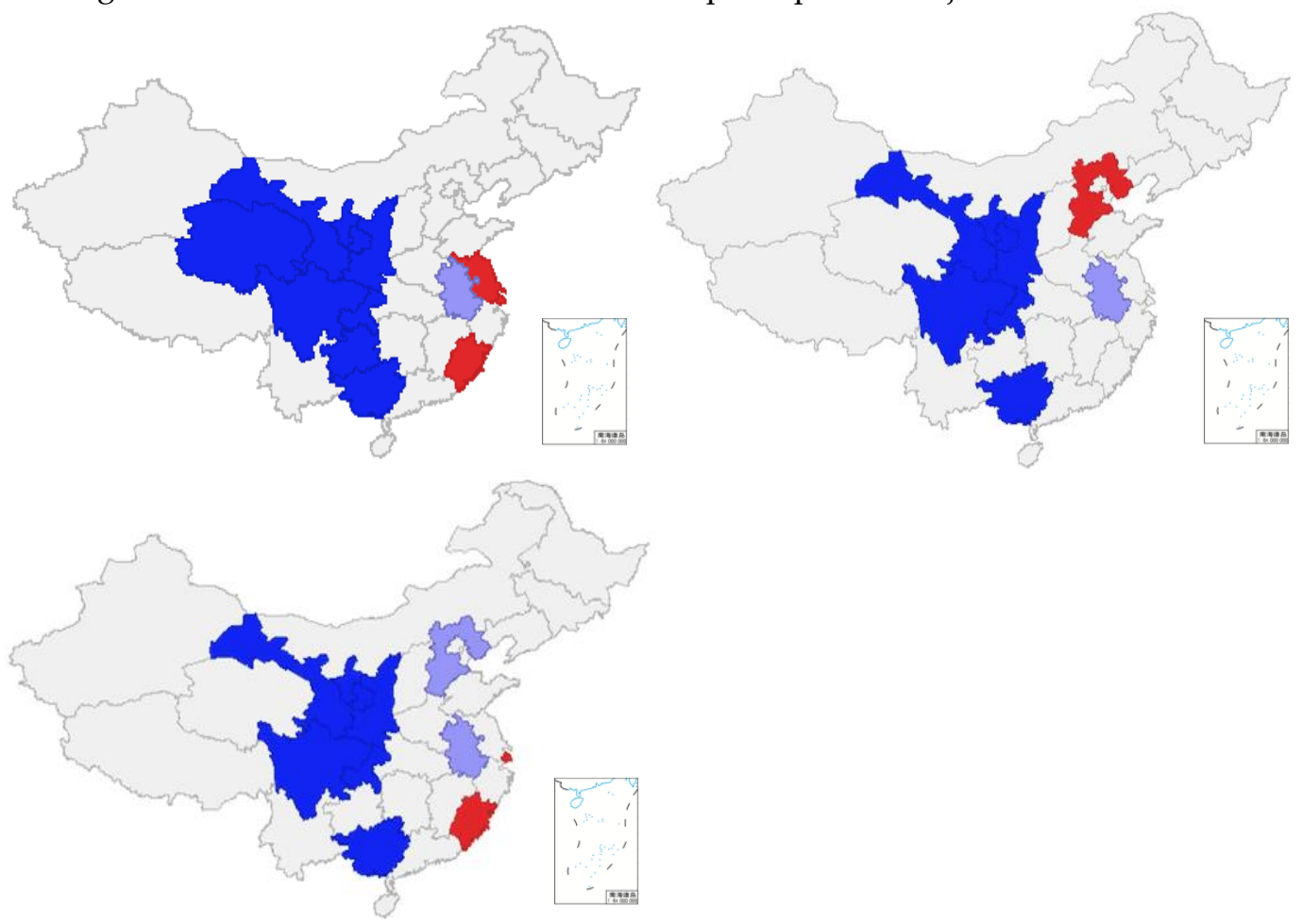

Figure 8. Comparison of local LISA in 2003, 2008 and 2013.

In the local Lisa cluster diagram as Figure 8, the red part is the high-high area, the blue part is the low-low area, indicating that there is a positive local space autocorrelation cluster center; the light purple part is the low high area, indicating that there is a negative local space autocorrelation cluster center; the gray part is the radiation area around the spatial cluster center. 

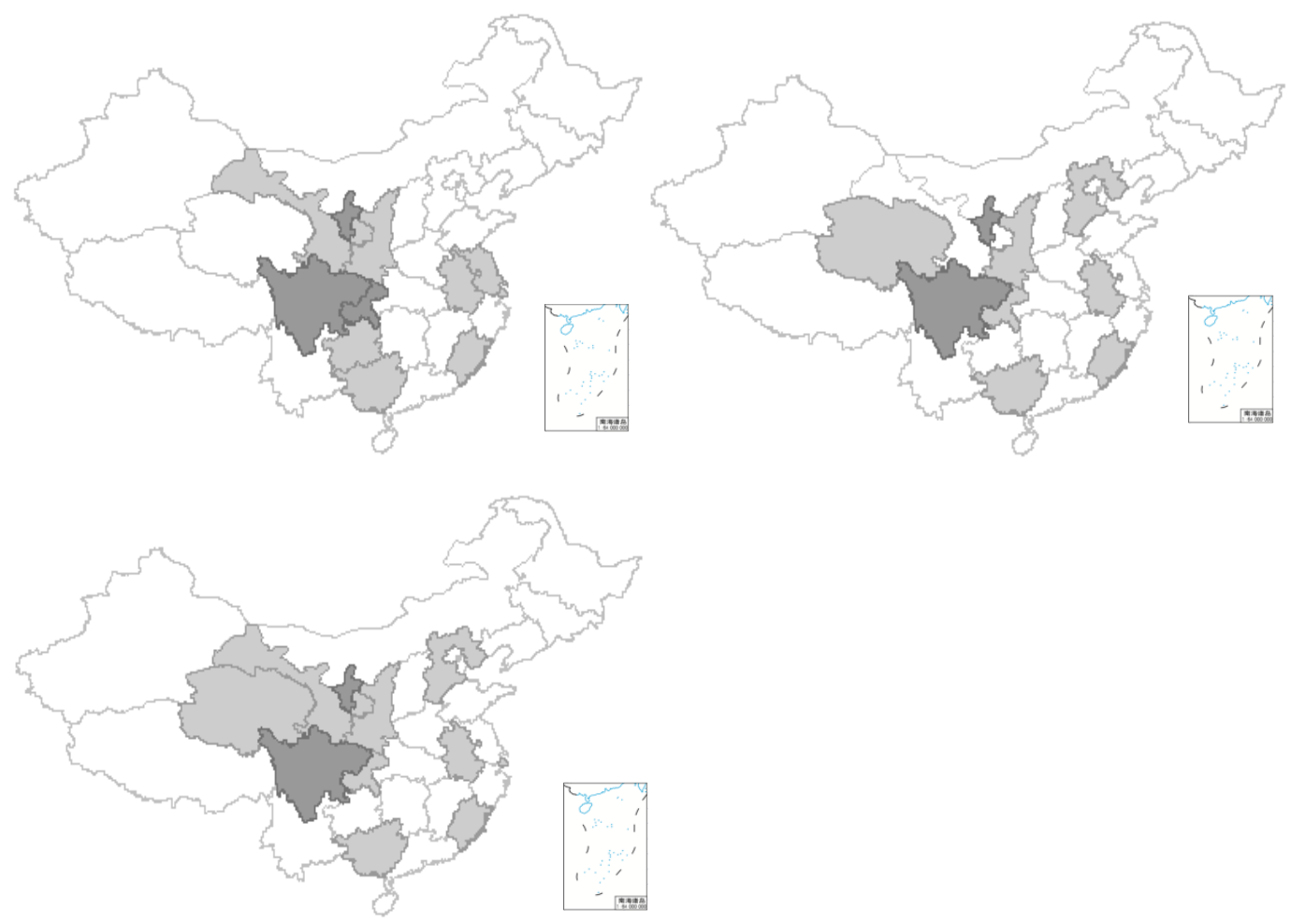

Figure 9. Significant comparison of local LISA in 2003, 2008 and 2013.

The significance map of local Lisa as Figure 9 can show the significance degree of the corresponding regional agglomeration. The dark gray area represents the agglomeration at the significance level of 0.01 , and the light gray area represents the agglomeration at the significance level of 0.05 .

It can be seen that the agglomeration centers of China's inter-provincial per capita GDP in the representative years are significant and have little change. The agglomeration centers of high per capita real GDP and their adjacent provinces and cities are basically concentrated in the eastern region, while the agglomeration centers of low per capita real GDP and their adjacent provinces and cities are generally concentrated in the western region. The regions with high concentration of producer services in China are basically consistent with the regions with positive spatial correlation of real GDP per capita, while the regions with low concentration of producer services are roughly coincident with the regions with negative spatial correlation of real GDP per capita. Therefore, the following issues are discussed in this paper: (1) is there spatial spillover in producer services agglomeration area? (2) Is the inter provincial economic growth affected by the spatial spillover of producer services agglomeration in neighboring provinces?

\subsection{Spatial econometric model}

Compared with the classical linear econometric model, which assumes that the samples are independent of each other, the spatial econometric model considers the spatial dependence among regions when processing the spatial data related to geographical location (Anselin 1988). This spatial dependence is also reflected in the lag term of the interpreted variable and the lag term of the error term, reflecting that the interpreted variable in this region is not only affected by the local explanatory variable, but also may be affected by the adjacent interpreted variable and its error impact. Therefore, when analyzing the spatial impact of productive service industry agglomeration on China's inter provincial economic growth, we need to consider the spatial distribution characteristics of producer services agglomeration, as well as the spatial spillover effect of productive service industry agglomeration on the economic growth of the surrounding areas.

After Cliff and Ord (1973) proposed a spatial measurement model for cross-section data, Anselin (1988), Elhorst (2003), Lesage and Pace (2009) etc. extended its improvement to panel data spatial 
measurement model, mainly including spatial lag model (SLM), spatial error model (SEM) and spatial Doberman model (SDM). SDM is a general form of SLM and SEM. It can be verified whether SDM can be simplified to SLM or SEM by Wald test or LR test (Burridge 1981). If the form of measurement model is SLM or SDM, the spatial effect of independent variables on dependent variables can be divided into direct effect and indirect effect (Lesage and Pace 2009). The direct effect measures the spatial effect of the change of explanatory variables on the interpreted variables, including the feedback effect of the local spatial effect on the interpreted variables when it is transferred to the adjacent areas and then returned to the local area; the indirect effect measures the spatial effect of the change of the local explanatory variables on the interpreted variables in all other areas; the sum of the direct effect and the indirect effect is called the total effect. In this paper, the total effect of producer services agglomeration on China's inter-provincial economic growth is divided into direct effect and indirect effect, in order to investigate and compare the degree and direction of different types of spatial effects.

\subsection{Selection, estimation and result analysis of spatial econometric model}

1. The choice of econometric model of space panel

Before choosing the econometric model of spatial panel, we need to test the spatial correlation. In the above, we have determined the spatial correlation of China's inter provincial economic growth through Moran 's I index test. Next, this paper will use the maximum likelihood LM-error test, LM-lag test, robust LM-error test and robust LM-lag test to judge the specific form of the spatial econometric model. The test results are shown in Table 3.

Table 3. Spatial correlation test results.

\begin{tabular}{ccc}
\hline Test & Statistics & p-value \\
\hline LM (lag) & 2.3335 & 0.127 \\
Robust LM (lag) & 0.6351 & 0.425 \\
LM (error) & 16.9216 & 0.000 \\
Robust LM (error) & 15.2232 & 0.000 \\
\hline
\end{tabular}

The test results in Table 3 show that LM (lag) and LM (error) statistics and p-values show that there is a spatial effect, and the spatial lag effect and spatial error effect are significant, the former is significant at the level of $10 \%$ and the latter is significant at the level of $1 \%$; and robust form of robot LM (error) passed the 1\% significance level test, while the result of robot LM (lag) failed to pass the $10 \%$ significance level test, that is, the original hypothesis that there is no spatial lag effect cannot be rejected. The comparison shows that for this paper, SEM is better than SLM.

Hausman test is applied to panel data to determine whether fixed effect model estimation or random effect model estimation should be used. The results of Hausman test show that the test statistic is 84.94 , prob $>\mathrm{chi}^{2}=0.0000$, indicating that the original hypothesis of random effect is rejected at $1 \%$ significance level, that is, panel data has fixed effect.

In conclusion, the SEM model of fixed effect panel is set as follows:

$$
\begin{aligned}
& \ln r p G D P=\beta_{0}+\beta_{1} \ln k_{i t}+\beta_{2} \ln L_{i t}+\beta_{3} \ln G_{i t}+\beta_{4} \text { trans }_{i t}+\beta_{5} \text { mail }_{i t}+\beta_{6} r d_{i t}+\beta_{7} \text { gov }_{i t}+ \\
& \beta_{8} \text { open }_{i t}+\beta_{9} e d u_{i t}+u_{i}+v_{t}+e_{i t}, e_{i t}=\lambda W \varepsilon_{i t}+\varepsilon_{i t}
\end{aligned}
$$

Where $u_{i}$ is the individual effect, $v_{t}$ is the time effect, $\mathrm{W}$ is the spatial distance weight matrix, $\varepsilon_{i t}$ is the random error term, $\varepsilon_{i t} \sim N\left(0, \sigma^{2} I_{n}\right)$.

2. Analysis of the estimation results of the econometric model of space panel

We use Matlab R2014b and its spatial measurement software package to estimate and test the spatial panel model. When the samples are randomly taken from the population, it is more appropriate to choose the random effect model, while when the samples are composed of some specific individuals or the samples are the population, it is more appropriate to choose the fixed effect model (Baltagi 2009). The research sample of this paper consists of 31 provincial administrative regions in China. Obviously, 
the fixed effect model is a better choice. In addition, according to the different control of fixed effect model to two kinds of non-observation effects, it can be divided into four types: non fixed effect, space fixed time non fixed effect, time fixed space non fixed effect and space and time double fixed effect.

Next, we need to establish panel SDM model and SEM model for comparison, through Wald test and LR test to determine which is more suitable for this study.

The specific form of SDM is as follows:

$$
\begin{aligned}
& \operatorname{lnrpGDP}_{2} \beta_{0}+\rho W \times \operatorname{lnrpGDP}+\beta_{1} \operatorname{lnk}_{i t}+\beta_{2} \ln _{i t}+\beta_{3} \ln G_{i t}+\beta_{4} \text { trans }_{i t}+\beta_{5} \text { mail }_{i t}+ \\
& \beta_{6} r d_{i t}+\beta_{7} \operatorname{lngov}_{i t}+\beta_{8} \text { open }_{i t}+\beta_{9} e d u_{i t}+\theta_{1} W \times \ln k_{i t}+\theta_{2} W \times \ln L_{i t}+\theta_{3} W \times \operatorname{lnG}_{i t}+ \\
& \theta_{4} W \times \text { trans }_{i t}+\theta_{5} W \times \text { mail }_{i t}+\theta_{6} W \times r d_{i t}+\theta_{7} W \times \text { gov }_{i t}+\theta_{8} W \times \text { open }_{i t}+\theta_{9} W \times e d u_{i t}+ \\
& u_{i}+v_{t}+\varepsilon_{i t}
\end{aligned}
$$

Table 4. Wald test and LR test of SDM.

\begin{tabular}{cccc}
\hline & Spatial fixed effect & Time fixed effect & $\begin{array}{c}\text { Spatial and time } \\
\text { fixed effects }\end{array}$ \\
\hline Wald test spatial lag & 23.3798 & 78.7544 & 83.1454 \\
$(\mathrm{p}=0.0054)$ & $(\mathrm{p}=0.0000)$ & $(\mathrm{p}=0.0000)$ \\
LR test spatial lag & $21.9496(\mathrm{p}=0.0090)$ & $74.2613(\mathrm{p}=0.0000)$ & 65.9617 \\
Wald test spatial & 12.8980 & 78.8267 & $(\mathrm{p}=0.0000)$ \\
error & $(\mathrm{p}=0.1673)$ & $(\mathrm{p}=0.0000)$ & 82.2740 \\
LR test spatial error & 15.5565 & 73.8517 & 68.4319 \\
& $(\mathrm{p}=0.0767)$ & $(\mathrm{p}=0.0000)$ & $(\mathrm{p}=0.0000)$ \\
\hline
\end{tabular}

${ }^{2}$ Figures in parentheses are $\mathrm{p}$-values.

Table 4 reports SDM of the Wald test and LR test results. For the hypothesis test with the null hypothesis of " $H_{0}: \theta=0$ ", the Wald test and LR test in three forms of spatial fixed effect, time fixed effect and spatial and time fixed effects passed the $1 \%$ significance test, rejected the null hypothesis that SDM can be simplified as SLM. For the hypothesis test with the null hypothesis of " $H_{0}: \theta+\rho \beta=$ 0 ", the Wald test and LR test under the fixed time and double fixed effects both passed the $1 \%$ significance test. The hypothesis that SDM can be simplified as SEM was rejected, while Wald test under the spatial fixed effect failed to pass the 10\% significance test, and LR test passed the $10 \%$ significance test.

According to the above analysis, SDM is the optimal model for this study, so we will focus on the estimation and in-depth discussion of SDM. In order to facilitate comparison, the estimation results of the SEM model under the fixed spatial effect are also given. In addition, the model (3) is estimated by the standard panel data measurement model, and four estimation results of the non-spatial panel data model are given comparing as Table 5 .

Table 5. Estimation and test of non-spatial panel model.

\begin{tabular}{ccccc}
\hline & $\begin{array}{c}\text { Non-spatial } \\
\text { effect }\end{array}$ & $\begin{array}{c}\text { Spatial fixed } \\
\text { effect }\end{array}$ & $\begin{array}{c}\text { Time fixed } \\
\text { effect }\end{array}$ & $\begin{array}{c}\text { Spatial and } \\
\text { time fixed } \\
\text { effect }\end{array}$ \\
\hline C & $5.971373^{* * *}$ & & & \\
ln_k & $0.438441^{* * *}$ & $0.162983^{* * *}$ & $0.607182^{* * *}$ & $0.114994^{* * *}$ \\
ln_L & $0.120006^{* * *}$ & $0.037453^{* *}$ & $0.105221^{* * *}$ & $0.043424^{* *}$ \\
ln_G & $0.084165^{* * *}$ & $-0.017051^{* *}$ & $0.060455^{* * *}$ & $-0.016874^{* * *}$ \\
trans & $-0.000001^{* * *}$ & $0.000001^{* * *}$ & $-0.000001^{* * *}$ & $0.000001^{* *}$ \\
mail & -0.000033 & $-0.000035^{* * *}$ & 0.000001 & $-0.000022^{* *}$ \\
rd & -0.000038 & $-0.000210^{* *}$ & -0.000070 & $-0.000152^{* * *}$ \\
gov & $-0.000128^{* * *}$ & $-0.000028^{*}$ & 0.000024 & $-0.000038^{* *}$ \\
\hline
\end{tabular}




\begin{tabular}{|c|c|c|c|c|}
\hline & $\begin{array}{c}\text { Non-spatial } \\
\text { effect }\end{array}$ & $\begin{array}{c}\text { Spatial fixed } \\
\text { effect }\end{array}$ & $\begin{array}{c}\text { Time fixed } \\
\text { effect }\end{array}$ & $\begin{array}{c}\text { Spatial and } \\
\text { time fixed } \\
\text { effect }\end{array}$ \\
\hline open & $0.000019^{* * *}$ & 0.000001 & $0.000014^{* * *}$ & $-0.000004^{* *}$ \\
\hline edu & 0.000069 & $0.000149^{* * *}$ & $-0.000165^{*}$ & $0.000185^{* * *}$ \\
\hline $\mathrm{R}^{2}$ & 0.8487 & 0.8153 & 0.8872 & 0.5336 \\
\hline LogL & 96.7280 & 527.8393 & 154.5769 & 564.0712 \\
\hline$\sigma^{2}$ & 0.0342 & 0.0027 & 0.0243 & 0.0022 \\
\hline $\mathrm{DW}$ & 2.1016 & 1.4820 & 2.3712 & 1.7483 \\
\hline
\end{tabular}
level of $10 \%, 5 \%$ and $1 \%$.

In order to avoid the influence of endogenous variables on the estimation results, the above spatial measurement models are estimated by the maximum likelihood estimation method (ML), and the estimation results of all spatial panel measurement models are shown in Table 6. In this paper, the standard panel data econometric model passed Stata 12.1, and all spatial panel data econometric models passed the estimation and test of Matlab R2014b.

Table 6. Summary of estimation results of SEM and SDM.

\begin{tabular}{|c|c|c|c|c|c|}
\hline \multirow{2}{*}{$\begin{array}{c}\text { Model } \\
\text { Variables }\end{array}$} & \multicolumn{2}{|l|}{ SEM } & \multicolumn{2}{|c|}{ SDM } & \multirow[b]{2}{*}{$\begin{array}{c}\text { Spatial and } \\
\text { time fixed } \\
\text { effect }\end{array}$} \\
\hline & $\begin{array}{c}\text { Spatial fixed } \\
\text { effect }\end{array}$ & $\begin{array}{c}\text { Non-fixed } \\
\text { effect }\end{array}$ & $\begin{array}{c}\text { Spatial fixed } \\
\text { effect }\end{array}$ & $\begin{array}{c}\text { Time fixed } \\
\text { effect }\end{array}$ & \\
\hline $\mathrm{C}$ & & $2.296074^{* * *}$ & & & \\
\hline ln_k & $0.149898^{* * *}$ & $0.533663^{* * *}$ & $0.121388^{* * *}$ & $0.536862^{* * *}$ & $0.122836^{* * *}$ \\
\hline ln_L & $0.044807^{* * *}$ & $0.205989^{* * *}$ & 0.020331 & $0.207045^{* * *}$ & 0.026599 \\
\hline ln_G & $-0.019815^{* * *}$ & $0.039308^{* * *}$ & $-0.015482^{* *}$ & $0.036967^{* * *}$ & $-0.010102^{*}$ \\
\hline trans & $0.000001^{* * *}$ & $-0.000001^{* * *}$ & $0.000001^{* * *}$ & $-0.000001^{* * *}$ & $0.000001^{* * *}$ \\
\hline mail & $-0.000022^{*}$ & 0.000035 & -0.000017 & 0.000033 & -0.000019 \\
\hline $\mathrm{rd}$ & $-0.000137^{* * *}$ & -0.000092 & $-0.000150^{* * *}$ & -0.000059 & -0.000063 \\
\hline gov & -0.000020 & 0.000014 & -0.000017 & 0.000003 & $-0.000038^{* * *}$ \\
\hline open & -0.000003 & $0.000013^{* * *}$ & $-0.000004^{* *}$ & $0.000014^{* * *}$ & $-0.000006^{* * *}$ \\
\hline edu & $0.000099^{*}$ & -0.000078 & $0.000105^{*}$ & -0.000083 & $0.000131^{* *}$ \\
\hline $\mathrm{W}^{*} \ln \_\mathrm{k}$ & & $-0.176753^{* *}$ & $-0.106792^{* * *}$ & 0.020189 & -0.006737 \\
\hline$W^{*} \ln \_L$ & & -0.017597 & -0.055715 & 0.048547 & $0.164495^{*}$ \\
\hline$W^{*} \ln \_G$ & & $-0.079926^{* *}$ & 0.037512 & $-0.083789^{*}$ & $0.049586^{*}$ \\
\hline $\mathrm{W}^{*}$ trans & & -0.000001 & -0.000000 & 0.000000 & $0.000005^{* * *}$ \\
\hline $\mathrm{W}^{*}$ mail & & $-0.000097^{*}$ & 0.000017 & $-0.000265^{*}$ & -0.000078 \\
\hline $\mathrm{W}^{*} \mathrm{rd}$ & & 0.000212 & -0.000245 & 0.000259 & $0.001154^{* * *}$ \\
\hline$W^{*}$ gov & & -0.000114 & -0.000021 & -0.000241 & $-0.000515^{* * *}$ \\
\hline$W^{*}$ open & & $0.000035^{* * *}$ & 0.000005 & $0.000052^{* * *}$ & $-0.000039^{* * *}$ \\
\hline$W^{*}$ edu & & -0.000271 & $0.000320^{* *}$ & 0.000015 & $0.001527^{* * *}$ \\
\hline$\varrho$ & & $0.364977^{* * *}$ & $0.567975^{* * *}$ & 0.155966 & $0.336981^{* *}$ \\
\hline$\lambda$ & $0.634977^{* * *}$ & & & & \\
\hline $\mathrm{R}^{2}$ & 0.9873 & 0.9115 & 0.9903 & 0.9140 & 0.9921 \\
\hline $\log L$ & 551.75752 & 186.56824 & 559.68267 & 192.64554 & 598.44283 \\
\hline$\sigma^{2}$ & 0.0024 & 0.0194 & 0.0023 & 0.0195 & 0.0017 \\
\hline
\end{tabular}

This paper focuses on the relationship between the agglomeration of producer services and economic growth. From the coefficient value $(0.049586)$ and its significance (significantly positive at the level of $10 \%$ ) of the spatial lag term $W^{*} \ln G$ of producer services reported in the last column of table 6, it can be seen that there is a significant interaction effect between the agglomeration of producer services in neighboring areas and the agglomeration of producer services in this area This kind of spatial interaction between regions will promote the economic growth of the region. 
Productive service industry agglomeration has passed the significance level test of at least $10 \%$ in both the general panel data model as Table 5 and the spatial panel data model as Table 6, which confirms that producer services agglomeration in China has played a significant role in the provincial economic growth through the spatial agglomeration effect.

The above empirical test results also show that there are significant spatial spillovers and spatial interactive growth in producer services agglomeration. From the last column of table 6, the spatial lag coefficient (i.e. Q) of per capita real GDP is 0.336981 , which is significantly positive at the level of $5 \%$, indicating that there is a significant interaction effect between the economic growth of this region and that of adjacent regions, and the economic growth of adjacent regions does have an interaction effect, and the improvement of the economic level of adjacent regions will promote the economic growth level of this region Improvement.

In the estimation results of SDM, the parameter estimation of explanatory variable cannot represent the marginal effect of the influence on the explanatory variable, and the analysis of its coefficient is meaningless. Table 7 shows the direct effect, indirect effect and total effect decomposition results of the explanatory variables under the double fixed effects of space and time on the provincial economic growth.

Table 7. Decomposition of spatial and time fixed effects (SDM).

\begin{tabular}{cccc}
\hline Variables & Direct effect & Indirect effect & Total effect \\
\hline ln_k & $0.123246^{* * *}$ & -0.038698 & 0.084548 \\
ln_L & 0.024722 & 0.115665 & $0.140387^{*}$ \\
ln_G & $-0.011145^{*}$ & $0.042285^{*}$ & $0.031140^{*}$ \\
trans & $0.000001^{* * *}$ & $0.000003^{* * *}$ & $0.000004^{* * *}$ \\
mail & -0.000018 & -0.000052 & -0.000070 \\
rd & $-0.000081^{*}$ & $0.000911^{* * *}$ & $0.000829^{* * *}$ \\
gov & $-0.000030^{*}$ & $-0.000390^{* * *}$ & $-0.000420^{* * *}$ \\
open & $-0.000005^{* * *}$ & $-0.000029^{* * *}$ & $-0.000034^{* * *}$ \\
edu & $0.000109^{* *}$ & $0.001148^{* * *}$ & $0.001257^{* * *}$ \\
\hline
\end{tabular}

From the direct effect part of the spatial effect decomposition results in Table 7, the direct effect coefficient of the agglomeration of productive services on the region's economic growth is -0.011145 , and it is significantly negative at a significance level of $10 \%$. It is important to point out that the direct effect of the agglomeration of productive service industries is different from its coefficient estimation because this direct effect includes not only the effect of the agglomeration of productive service industries on the region's economic growth, but also the feedback effect. The feedback effect is due to the spatial effect of the clustering of productive service industries in the region, which is transmitted to neighboring regions and then returns to the region to affect the region's economic growth. The degree of feedback effect is determined by two parts, one part is attributed to the coefficient of the explanatory variable $W^{*} \ln r r p G D P$ (@), and the other part is attributed to the coefficient of the productive service industry agglomeration spatial lag term $W^{*} n_{-} G$.

From the indirect effect part of the spatial effect decomposition results in Table 7, the spillover effect coefficient of the agglomeration of productive services to the region's economic growth is 0.042285 , and it is significantly positive at a significance level of $10 \%$. The indirect effect of the agglomeration of production and service industries is also called the spillover effect, which measures the degree of impact of changes in the production service industry agglomeration on the economic growth of all other regions. The increase of $1 \%$ will indirectly promote the economic growth of neighboring areas by $0.04 \%$ through spatial interaction. The indirect effect of producer services agglomeration is greater than the direct effect as a whole, which is determined by the nature of producer services itself. For example, financial industry and real estate industry have higher requirements for the level of human capital and the timely updating of knowledge and technology information. The spillover effect of producer services in the economically developed areas plays a leading role in the development of related industries in the surrounding areas. The intra-industry and 
inter-industry spillover effects can strengthen the connection between production and consumption, and better serve as an effective connection and coordination between different regions and sectors.

In addition, the estimation results of the spatiotemporal double fixed-effect SDM model show that there are also significant spatial interactions in explanatory variables such as labor input $L$ and traffic density trans. This shows that there are many uncertain spatial impact factors in our actual economic development, and these factors also have a certain impact on the spatial effect of the production service industry agglomeration. The indirect effect coefficients of infrastructure, R\&D investment and education investment are all significantly positive and much larger than the direct effects, indicating that the spillover effects of infrastructure, $R \& D$ investment and education investment in this region have significantly improved the economic growth of surrounding areas. The indirect effect coefficients of government expenditure and opening to the outside world are both significantly negative and much larger than the direct effects, indicating that government expenditure and spillover effects of opening up in the region have a restraining effect on the economic growth of the surrounding areas.

The above empirical results show that there is indeed a space spillover phenomenon of economic growth in the cluster of productive service industries, and the benefits of this cluster of productive service industries also spill over into neighboring regions with economic interaction.

\section{Conclusions}

Based on the panel data of 31 provinces (cities, autonomous regions) in China from 2003 to 2013, this paper analyzes the spatial impact of producer services agglomeration on inter provincial economic growth, as well as the direct and spillover effects of producer services agglomeration on regional economic growth. The results show that: first, the impact of spatial correlation cannot be ignored, and the level of inter provincial economic growth in China has significant spatial correlation. Secondly, the spatial spillover phenomenon of economic growth does exist in producer services agglomeration, and the interaction phenomenon of economic growth exists between neighboring provinces. Thirdly, the agglomeration of productive service industries has a significant difference in the direct spatial effect and spatial spillover effect of regional economic growth, and the direct effect is significantly negative, indicating that the agglomeration of productive service industries has a direct inhibitory effect on the region's economic growth through multiple channels. The indirect effect is significantly positive and much larger than the direct effect, which indicates that the agglomeration of productive service industries has a significant driving effect on the economic growth of neighboring areas.

At the present stage of China's economic development, the spatial agglomeration of productive service industries cannot be ignored, and regions should develop corresponding productive service industries based on their comparative advantages. The key to using producer services to drive economic growth lies in the rational adjustment and development of the spatial agglomeration structure of producer services. By controlling the agglomeration factors of producer services with significant spatial impact, regional resources can be integrated to the greatest extent to promote the upgrading of industrial structure and provincial economic growth, so as to achieve high-quality economic development.

\section{References}

Anselin Luc. 1988. Spatial Economics: Mehods and Models. Netherlands: Springer

Anselin Luc, and Florax Raymond. 1995. Small Sample Properties of Tests for Spatial Dependence in Regression Models. New Directions in Spatial Econometrics. Berlin: Springer

Aslesen Heidi Wiig, and Isaksen Arne. 2007. New Perspectives of Knowledge-intensive Services and Innovation. Geografiska Annaler Series B Human Geography: 89(s1), 45-58. https://doi.org/10.1111/j.1468-0467.2007.00259.x.

Baltagi Badi. H. 2009. A Companion to Econometric Analysis of Panel Data. New York: John Wiley \& Sons Press.

Brülhart Marius, and Shergami Federica. 2009. Agglomeration and Growth: Cross-country Evidence. Journal of Urban Economics: 65, 48-63. https://doi.org/10.1016/j.jue.2008.08.003.

Chen Jianjun, Chen Guoliang, and Huang Jie. 2009. Research on the agglomeration of producer services and its influencing factors from the perspective of new economic geography: Empirical Evidence from 222 cities in China. Management World: 4. 
Cliff Andrew D., and Ord J. K. 1973. Spatial Autocorrelation. London: Pion Publishers.

Elhorst J Paul. 2003. Specification and estimation of spatial panel data models. International Regional Science Review: 26(3): 244-268. https://doi.org/10.1177/0160017603253791.

Ellison Glenn, and Glaser Edward L. 1997. Geographic Concentration in U.S. Manufacturing Industries: A Dartboard Approach. Journal of Political Economy: 105(5), 889-927. https://doi.org/10.1086/262098.

Han Feng, Hong Lianying, and Wen Ying. 2014. Agglomeration of Productive Service Industry Promotes Urbanization? Quantitative, Economic, Technical and Economic Research, No. 12.

Hanssens Heidi, Derudder Ben, and Witlox Frank. 2013. Are Advanced Producer Services Connectors for Regional Economies? An Exploration of the Geographies of Advanced Producer Service Procurement in Belgium. Geoforum: 47(2), 12-21. https://doi.org/10.1016/j.geoforum.2013.02.004.

Jiang Jing, Liu Zhibiao, Yu Mingchao. 2007. Producer services development and manufacturing efficiency improvement: Empirical Analysis Based on regional and industry panel data. World Economy, No. 8.

LeSage James, Pace Robert Kelley. 2009. Introduction to Spatial Econometrics. Baca Raton: CRC Press/Taylor \& Francis.

Rosenthal Stuart S., and Strange William C. 2004. Evidence on the Nature and Sources of Agglomeration Economies. In Handbook of Regional and Urban Economics, Vol 4, pp. 2119-2171. Amsterdam: North Holland. https://doi.org/10.1016/S1574-0080(04)80006-3.

Ying Long Gen. 2003. Understanding China's Recent Growth Experience: A Spatial Econometric Perspective. The Annals of Regional Science: 37, 613-628. https://doi.org/10.1007/s00168-003-0129-x. 